\title{
Bioconversion of Agricultural and Food Processing Wastes to Value-Added Products Using Solid State Fermentation Technology. A Review.
}

\author{
Nwachukwu, Ifeanyi ${ }^{1}$; Ekwenye, Uchechi N. ${ }^{2}$; Agomuo, Ngozi G. ${ }^{1}$ and \\ Ogbonna, Chinyere R. \\ ${ }^{I}$ Department of Biology/Microbiology, Abia State Polytechnic, Aba, Abia State, Nigeria. \\ ${ }^{2}$ Department of Microbiology, College of Natural Sciences, Michael Okpara Univesity of Agriculture, Umudike, \\ Umuahia, Abia State, Nigeria.
}

\begin{abstract}
Large volume/quantity of wastes is generated every year from the individual processing of agricultural and food wastes. However, most of these wastes can be used as animal feed or could be buried as an alternative for elimination from the environment. Analysis has shown that such wastes have composition rich in sugars, minerals and proteins hence should not be considered as wastes as such but raw materials for other industrial processes. The presence of suitable carbon sources, nutrients and moisture in these wastes provides conditions appropriate for the development of microorganisms for their utilization and conversion to valueadded product. Therefore, finding alternatives for the re-use of these wastes is an objective that has been strongly taken into consideration by many countries of the world, looking at the environmental and economical aspects. This principle has opened up great possibilities for the use of the so called wastes in solid state fermentation (SSF) processes. Therefore better knowledge is required on how to design and optimize the various process parameters in order to allow successful SSF to be carried out. However, development of adequate process control strategies is a major challenge. This review aims at taking a critical analysis of SSF and fulfilment of its potential in conversion of agricultural and food processing wastes to value added-products.
\end{abstract}

Keywords: Wastes, Microorganisms, Bioconversion, Solid state fermentation, Process parameters, Valueadded products.

\section{Introduction}

Solid state fermentation (SSF) can be defined as processes involving the growth of microbial cultures on a moist solid with little or no free water though capillary water may be present such as in mushroom cultivation, (Zadrazil et al., 1992) bread making (Rocken and Voysey, 1995) and production of cheeses (Tautorus, 1985). In other words, solid state fermentation (SSF) consists of microbial growth and product formation on solid particles in the absence (or near absence) of water, however, the substrate contains sufficient moisture to allow the microorganism's growth and metabolism (Pandey, 2003).

Agro-industrial and food processing wastes which are generated in large amounts have been found to be composed of materials that are rich in sugar, minerals, moisture and proteins. These components can serve as suitable nutrients for the growth and metabolism of some microorganisms particularly fungi species. However, filamentous fungi are the most important group of microorganisms used in SSF process owning to their physiological, enzymological and biochemical properties. Therefore agro-industrial and food processing wastes should not be considered as wastes since they can be used as solid supports, carbon/nutrient source in SSF processes for the production of various value-added compounds (Solange et al., 2016). Agro-industrial wastes are good source of raw materials for other industrial microbial-mediated processes.

\section{Generation And Chemical Composition Of Agro-Industrial And Food Processing Wastes}

Agro-industrial and food processing wastes are generated during the industrial processing of agricultural or animal/food products. Those derived from agricultural activities include materials such as straw, stem, stalk, leaves husks, shell peel, hint, seed/stones, pulp or stubble from fruits, legumes or cereals, bagasses etc. These wastes are mainly composed of compounds like sugars, fibres, proteins and minerals, which are materials of industrial interest. The interest lies on the facts that these wastes are largely available and their composition could be used in other processes hence the great interest on the re-use of these wastes, both from economical and environmental stand point. The economical part is related to the fact that these wastes could be used as cheap raw materials for the production of other value-added products, with the expectancy of reducing the production cost. While the environmental concern is because most of the agro-industrial and food processing waste contains phenolic and other potentially toxic compounds, which may cause deterioration of the environment when the wastes are discharged to the environment untreated. 
Analysis has shown that these agro-industrial and food processing wastes are mainly composed of cellulose, hemicellulose and lignin, being called lignocellulosic materials. However, the percentage of cellulose, hemicellulose and lignin is different to each waste since it varies from one plant species to another and also according to the process that the agricultural material was submitted (Table 1). Compositional variations equally depend on age, stage of growth and other conditions. In the lignocellulosic materials, these fractions are closely associated with each other constituting the cellular complex of the vegetal biomass and forming a complex structure that act as a protective barriers to cell destruction by microorganisms. Basically, cellulose forms a skeleton which is surrounded by hemicellulose and lignin.

Table 1: Some lignocellulosic wastes and their percentage compositions.

\begin{tabular}{|l|l|l|l|}
\hline Lignocellulosic waste & Cellulose (wt \%) & Hemicellulose (wt \%) & Lignin (wt \%) \\
\hline Barley straw & 33.8 & 21.9 & 13.8 \\
\hline Corn cobs & 33.7 & 31.7 & 6.1 \\
\hline Corn stalks & 35.0 & 16.8 & 7.0 \\
\hline Cotton stalks & 58.5 & 14.4 & 21.5 \\
\hline Oat straw & 36.2 & 27.1 & 17.5 \\
\hline Rice straw & 36.2 & 19.0 & 9.9 \\
\hline Rye straw & 37.6 & 30.5 & 19.0 \\
\hline Soya stalks & 34.5 & 24.8 & 19.8 \\
\hline Sugarcane bagasse & 40.0 & 27.0 & 10.0 \\
\hline Sunflower stalks & 42.1 & 29.7 & 13.4 \\
\hline Wheat straw & 32.9 & 24.0 & 8.9 \\
\hline
\end{tabular}

Source: (Nigam et al., 2009)

The presence of sugars, proteins, minerals and water make the agro-industrial waste a suitable environment for the development of microorganisms notably fungi species, which are able to quickly grow in these wastes. In addition, if the cultivation conditions are controlled, different products of the industrial interest may be produced, thereby avoiding the loss of potential energy sources.

\section{Benefits Of Solid State Fermentation}

Presently, solid state fermentation has been applied to large scale industrial processes globally due to its benefits. This bioprocess has been subject of several studies and it has been proved that SSF has the important advantage of leading to higher yields and productivities or better products characteristics than Submerged Fermentation $(\mathrm{SmF})$, which is characterized by the cultivation of the microorganisms in a liquid medium. Also SSF has lower capital and operating cost due the utilization of low cost agricultural and food processing wastes as substrates. The process makes use of low water volume and this has a great impact on the economy of the process mainly because of the smaller fermenter size, the reduced downstream processing, the reduced stirring and lower sterilization cost (Holker and Lenz, 2005; Nigam, 2009).

\section{Important Technical Aspects Of SSF That Need Consideation}

In spite of the many processing and biological advantages that SSF has over submerged fermentation $(\mathrm{SmF})$, there are necessary technical aspects that need to be considered. Firstly, the scaling-up of this bioprocess is not well developed and has a drawback associated with control of operations and fermentation variables. The common bioreactors used in SSF (packed-bed, horizontal drum and fluidized bed) have their limitations, hence there is necessity to develop novel bioreactors with better design. In view of this, research attention is now geared towards the development and implementation of effective control strategies of bioreactors operating in SSF conditions in large-scale and their design (Durand, 2003; Von Meien et al., 2004). More-so, an economical evaluation of the overall process is needed in order to determine its feasibility to a specific purpose.

Separation of biomass represents another challenge in SSF, being essential for the kinetic studies. Several indirect methods have been employed including glucosamine estimation, ergosterol estimation, protein/DNA estimation dry weight changes, $\mathrm{CO}_{2}$ evolution etc. But the estimation of oxygen intake and carbon dioxide evolution rate are considered to be the most accurate for the determination of growth of microorganism (Pandey et al., 2007) In addition, digital image processing has also been developed for measuring biomass in SSF (Couri et al., 2006).

There are various important factors to be considered for the development of a successful bioprocess under SSF conditions. Some of the most important include the selection of a suitable microorganism and solid support to be used. A diversity of microorganisms, including fungi, yeasts and bacteria are used in SSF process. However, due to the low moisture content in the SSF media, fungi are the most commonly used microorganisms because of their ability to grow in such environments. The selection of microorganism to be used in a SSF process though depends on the desired end product. For instance, filamentous fungi have great potential to 
produce bioactive compounds and thermostable enzymes of high scientific and commercial value, they are therefore the most preferred microorganisms used in SSF (Dinis et al., 2009; Zhao and Xia, 2009).

The process variables such as pre-treatment and particle-size of substrates, medium ingredients, supplementation of growth medium, sterilization of SSF medium, moisture content, water activity $\left(\mathrm{a}_{\mathrm{w}}\right)$, inoculums density, temperature, $\mathrm{pH}$, agitation and aeration have also to be considered for an efficient SSF process (Nigam and Pandey, 2009). Generally the production yields can be improved with a suitable choice of the substrate or mixture of substrates with appropriate nutrients. As a whole, the support material must present characteristic favourable for the microorganism's development, be economical and present a good availability, which might involve the screening of several agro-industrial wastes.

The moisture content and water activity $\left(\mathrm{a}_{\mathrm{w}}\right)$ also play an important role in SSF. The water requirements of the microorganism have been considered to be better defined in terms of water activity $\left(\mathrm{a}_{\mathrm{w}}\right)$ rather than water content in the solid substrate (Raimbault, 1998). This is because $a_{w}$ is the water available or accessible for the growth of the microorganism and affects the biomass development, metabolic reactions and the mass transfer processes. In nutshell, low $\mathrm{a}_{\mathrm{w}}$ values might induce the sporulation of the microorganism, while more elevated values may reduce the porosity of the system, which can produce oxygen transfer limitation.

Finally, the selection of the most appropriate downstream process for the final product obtained is also crucial when SSF processes are performed. The product obtained by SSF may be recovered from the solid fermented mass by extraction with solvent (aqueous or other solvents mixtures). The cost of purification depends on the quality of the obtained extract. For example, the presence and concentration of inert compounds in the extract increase the cost of purification and therefore the cost of recovery is increased.

\section{Modelling In Solid State Fermentation}

Modelling is an important tool to improve the chances of successfully transforming an SSF process from laboratory to a scaled-up commercial level. Basically, the emergence of modelling in SSF underscores the need of searching mathematical expressions that represent the system under consideration, focusing the following main problems:

(i) The representation of the microbial activity (Kinetic patterns and thermodynamic concerns).

(ii) Studies of the problems of heat accumulation and heterogeneous distribution in complex gas-liquid-solid multiphase bioreactor (or fermenter) systems.

(iii) The connection between the two systems above.

(iv) The selection of the best type of the fermenter (Koncsag \& Kirwan, 2010; Singhania et al., 2009).

The ability to predict the behaviour of SSF process can ascertain the validity of the system, while establishing different parameters that characterize the process and appropriate mechanisms for its development and control. The modelling of bioreactors employed in SSF processes can play a curial role in the analysis, design and development of bioprocesses for the treatment of agro-industrial and food processing waste. The development of models can also significantly reduce the number of wet experiments and in consequence will have a strong impact on time saving and costs of the process.

The modelling and optimization of simultaneous influence of temperature and moisture on microbial growth through a quantitative description has been also investigated as well as the effect of microbial biomass on the isotherm of the fermenting solid in SSF.

It is now obvious that modelling of the various parameters are of great importance in the scale-up and optimization of SSF bioreactors configuration for the production of a desired end product using agro-industrial and food processing wastes as solid support. Nevertheless, several issues still need to be analyzed and solved for improved modelling of SSF. Information regarding modelling in SSF has been limited because of the unavailability of suitable methods for direct measurement of the microorganism growth. This is due to the difficulty to separate the microorganism from the substrate and problems related to the determination of the substrate utilization rate. An alternative to overcome these problems is the determination of the microorganism cell growth by measuring the change in gaseous compositions inside the bioreactor, since it is well known that the fermentation kinetics is very sensitive to the variation in ambient and internal gas composition (Singhania et al., 2009).

\section{Current and Potential Applications of Agro-industrial and Food Processing Wastes in SSF Processes for Production of Value-added Products.}

SSF has two potential areas of application. One of them is for environmental control such as for the production of compost, ensiling and animal feed from solid wastes, bioremediation and biodegradation of hazardous compounds and biological detoxification of agro-industrial wastes. On the other hand, SSF may be utilized to obtain value-added compounds such as enzymes, mushrooms, amino acids, biopesticides, biofuels, biosurfactants, organic acids (citric acid, lactic acid, oxalic acid etc), flavours, colourants, aromatic compounds, biologically active secondary metabolites and other substances of interest to the food industry. 
In general, the various economic applications of SSF offer the potential of significantly improving and raising living standards with only a low technology input requirement (Mitchell, 1992). SSF is briefly associated with the production of traditional fermented foods such as Japanese 'koji', Indonesian 'tempeh', Indian 'ragi' and Nigerian 'fufu', 'dawadawa'.

\section{Conclusion}

Agro-industrial and food processing wastes are generated in large amounts every year. Finding alternatives for the re-use of these wastes is an objective that has been strongly taken into account by countries around the world, considering environmental and economical aspects. The agro-industrial and food wastes reuse in SSF processes is of particular interest due to their availability, low cost and characteristics that allow obtaining different value-added compounds, besides being an environment friendly alternative for their disposal. This is feasible because SSF is a well-adapted process for cultivation of filamentous fungi on vegetal materials which are broken down by excreted hydrolytic enzymes. Also, filamentous fungi are the most important group of microorganisms used in SSF process owning to their physiological, enzymological and biochemical properties. Additionally, the agro-industrial and food processing wastes may be used in these processes as solid support, carbon, nitrogen and/or mineral sources, which would allow obtaining more economical fermentation processes avoiding the use of expensive chemical components in the media formation. As a consequence, more economical processes could be established for implementation on industrial scale well as in a sustainable manner.

\section{References}

[1]. Dinis, M. J., Bezerra, R. M. F., Nunes, F., Dias, A. A., Guesdes, C. V., Ferreira, L. M. M., Cone, J. W., Marques, G. S. M., Barros, A. R. N. and Rodrigues, M. A. M. (2009). Modification of wheat straw lignin by solid state fermentation with white-rot fungi. Bioresource Technology, 100, 4829- 4835

[2]. Durand, A. (2003). Bioreactor designs for solid state fermentation. Biochemical Engineering Journal, 13, 113-125.

[3]. Holker, U. and Lens, J. (2005). Solid-state fermentation: are there any biotechnological advantages? Current Opinion in Microbiology, 8, 301-306

[4]. Koncsag, C. I. and Kirwan, K. (2010). Heat and mass transfer study during wheat straw solid substrate fermentation with $P$. ostreatus, Chemical Bulletin of "Politechnica" University of Timisoara, 55, 1-4

[5]. Mitchell, D. A., Krieger, N., Stuart, D. M. and Pandey, A. (2000). New developments in solid-state fermentation: II. Rational approaches to the design and scale-up of bioreactors. Process Biochemistry, 5, 1211-1225

[6]. Nigam, P. S. (2009). Production of bioactive secondary metabolites, In: Biotechnology for Agro-industrial Residues Utilization, Nigam, P. S., and Pandey, A. (Eds.) pp. 129 - 145 Springer, Netherlands.

[7]. Nigam, P. S. and Pandey, A. (2009). Solid-state fermentation technology for bioconversion of biomass and agricultural residues, In: Biotechnology for Agro- Industrial Residues Utilization, Nigam, P. S. and Pandey, A. (Eds.) pp . 197- 221, Springer, Netherlands.

[8]. Nigam, P. S., Gupta, N. and Anthwal, A. (2009). Pre-treatment of agro-industrial residues, In: Biotechnology for Agro-Industrial Residues Utilization, Nigam, P. S. and Pandey, A. (Eds.) pp. 13-33, Springer, Netherlands.

[9]. Pandey, A. (2003). Solid state fermentation. Biochemical Engineering Journal, 13, 81-84

[10]. Pandey, A., Soccol, C. R. and Larroche, C. (2007). Current Development in Solid-state Fermentation, In: Current development in solid-state fermentation, Pandey, A., Soccol, C. R. and Larroche, C. (Eds.), pp. 13-25, Springer Science/Asiatech Publishers, Inc., New York, USA/New Delhi, India.

[11]. Rainmbault, M. (1998). General and microbiological aspects of solid substrate fermentation. Electronic Journal of Biotechnology, 1, 174- 188 .

[12]. Rocken, W. and Voysey, P. A. (1995). Solid substrate fermentations, enzyme production and food enrichment. J. Appl. Bacteriol. Symp. Suppl. 79, 385-485.

[13]. Singhania, R. R., Patal, A. K., Soccol, C. R. and Pandey, A. (2009). Recent advances in solid-state fermentation: review. Biochemical Engineering Journal, 44, 13- 18.

[14]. Solange, I. M., Lina, F. B., Silvia, M. and Jose, A. T. (2012). Use of Agro-Industrial Wastes in Solid State Fermentation Processes. Institute for Biotechnology and Bioengineering,(IBB)Centre of Biological Engineering Universityo Minho, Portugal. www.intechopen.com. Retrieved 22-08-2016.

[15]. Tautorus, T. E. (1985). Solid substrate fermentations, enzyme production, food enrichment. Advanced Biotechnology Processes 5, 227-27.

[16]. von Mein, O. F., Luz Jr, L. F. L., Mitchell, D. A., Perez-Correa, J. R., Agosin, E., Fernandez-Fernandez, M. and Arcas, J. A. (2004). Control strategies for intermittently mixed, forcefully aerated solid-state fermentation bioreactors based on the analysis of a distributed parameter model. Chemical Engineering Science, 59: 449-4504

[17]. Zadrazil, F., Ostermann, D. and Compare, G. D. (1992). In H. W. Doelle, D. A. Mitchell and C. E. Rolz eds., Solid Substrate Cultivation, Elsevier, London, pp. 28-19.

[18]. Zhao, J. and Xia, L. (2009). Simultaneous saccharification and fermentation of alkaline-pretreated corn stover to ethanol using a recombinant yeast strain. Fuel Processing Technology, 99, 1193-1197.

[19]. Mitchell, D. A. (1992). In Solid Substrate Cultivation. Elsevier Sci. Publ. Ltd London and New York, pp. 17-20. 